DOI: $\underline{\text { https://doi.org/10.24867/04FA08Mihelcic }}$

\title{
TRODIMENZIONALNI DEKORATIVNI ZIDNI PANELI - PROIZVODNJA, MATERIJALI I PRIMJENA
}

\section{THREE-DIMENSIONAL DECORATIVE WALL PANELS - PRODUCTION, MATERIALS AND APPLICATIONS}

\author{
Andrija Mihelčić, Fakultet tehničkih nauka, Novi Sad
}

\section{Oblast - ARHITEKTURA I URBANIZAM}

Kratak sadržaj - Ovaj rad ima za namjeru preispitati elemente prihvatljivosti i dostupnosti dekorativnih $i$ ornamentalnih elemenata $u$ arhitektonskoj praksi. Kroz praktičan rad napravljen je osvrt na tehnologiju proizvodnje dekorativnih panela za male serije.

Ključne reči: Ornament, Dekoracija, Dizajn, Dizajn interijera, Arhitektonska estetika, Digitalni dizajn, Digitalna fabrikacija, Mašinska obrada, CNC, Proizvodnja dekorativnih panela

Abstract - This paper intends to re-examine the elements of acceptability and availability of decorative and ornamental elements in architectural practice, and through practical work reviews the production technology for small series production of decorative panels.

Keywords: Ornament, Decoration, Design, Interior design, Architecture aesthetics, Digital design, Digital fabrication, Machining, CNC, Production of decorative panels

\section{UVOD}

Danas, nova arhitektonska estetika rađa se potaknuta rapidnim razvojem informacijskih tehnologija, sve većom dostupnošću procesorske snage i pojavom računalno kontroliranih strojeva (eng. Numerically Controlled Machines) [6,7,8]. Ove nove mogućnosti u potpunosti mijenjaju arsenal alata s kojima barata suvremeni arhitekt, pa tako Laserski rezači, 3d printeri, CNC glodalice i robotske ruke omogućavaju da jedan arhitektonski biro preuzme potpunu kontrolu nad projektantskim i proizvodnim procesima. Takav razvoj događaja potaknuo je niz progresivnih arhitekata na promišljanje o dekoraciji i ornamentu kako nikada prije nije bilo moguće [6]. Prije pojave Moderne, svaki dekorativni komad trebao je biti izrađen u suradnji sa obrtnicima i umjetnicima [8]. U procesu se trošilo jako puno vremena na pregovaranje $i$ usklađivanje vizije arhitekta i umjetnika, dok je danas arhitektima cijeli proces dostupan ,sa stola“.

Cilj je rada istražiti mogućnosti dizajna i proizvodnje dekorativnih zidnih panela za male serije inspiriranih valovitim površinama koristeći se jednostavnim i dostupnim proizvodnim alatima i materijalima.

\section{NAPOMENA:}

Ovaj rad proistekao je iz master rada čiji mentor je bio dr Bojan Tepavčević, van. prof.
U nastavku je opisan dizajnersko-proizvodni proces panela te su izloženi komparativni rezultati 4 različita uzorka panela.

\section{DIZAJN I PROIZVODNJA DEKORATIVNIH ZIDNIH PANELA}

Razvoj tehnologije i postepeno opadanje cijena proizvodnih strojeva omogućavaju sve veću zastupljenost istih na širem tržištu. Strojeve koje se prije 20-tak godina moglo pronaći jedino u profesionalnim proizvodnim postrojenjima, danas nije neobično vidjeti u hobi radionicama $\mathrm{i}$ privatnim malim obrtima. Takav razvoj situacije pogoduje dizajnerima, arhitektima i umjetnicima koji svoje ideje žele primijeniti na izolirane projektne slučajeve i prilikom izvedbe unikatnih proizvodnih komada. Za proizvodnju dekorativnih zidnih panela za male serije, od materijalnih resursa dovoljno je posjedovati jedan CNC stroj srednjih do većih dimenzija, računalo sa instaliranom softverskom podrškom te osnovnu sirovinu za proizvodnju.

\subsection{Dizajnersko-proizvodni proces}

Za realizaciju zadatka korištena je sljedeća oprema:

- Za dizajn i istraživanje forme panela:

Rhinoceros 6 + Grasshopper

- Priprema za proizvodnju i generiranje NC koda: RhinoCAM 2018

- Proizvodnja: 3-osni NC stroj radnog volumena 1000x1000x350mm i Mach3 NC kontroler

- Materijal: MDF medijapan 700kg/m3, 25mm

- Dimenzije uzorka: okrugla ploča Ø $300 \mathrm{~mm}$, površine $706.86 \mathrm{~cm} 2$

Generalni slijed operacija za dobivanje jednog obradka možemo podijeliti u tri osnovne faze: 1) Generiranje oblika, 2) Priprema za strojnu obradu, i 3) Strojna i ručna obrada. Vizualni prikaz procesa dostupan je putem dijagrama na sljedećoj strani.

\subsection{Generiranje oblika}

Visoko reljefna aperiodična valovita površina generirana je pomoću Grasshopper plug-ina za Rhinoceros koristeći multiplikaciju i modulaciju sinusnih funkcija.

Valovita površina dobivena korištenjem jedne sinusne funkcije i jednog izvora vala djeluje monotono i periodično. Dodavanjem izvora drugog vala monotonost površine se donekle razbija, no $\mathrm{i}$ dalje postoji vidljivi periodički uzorak po kojem se valovi šire i međusobno interferiraju. 


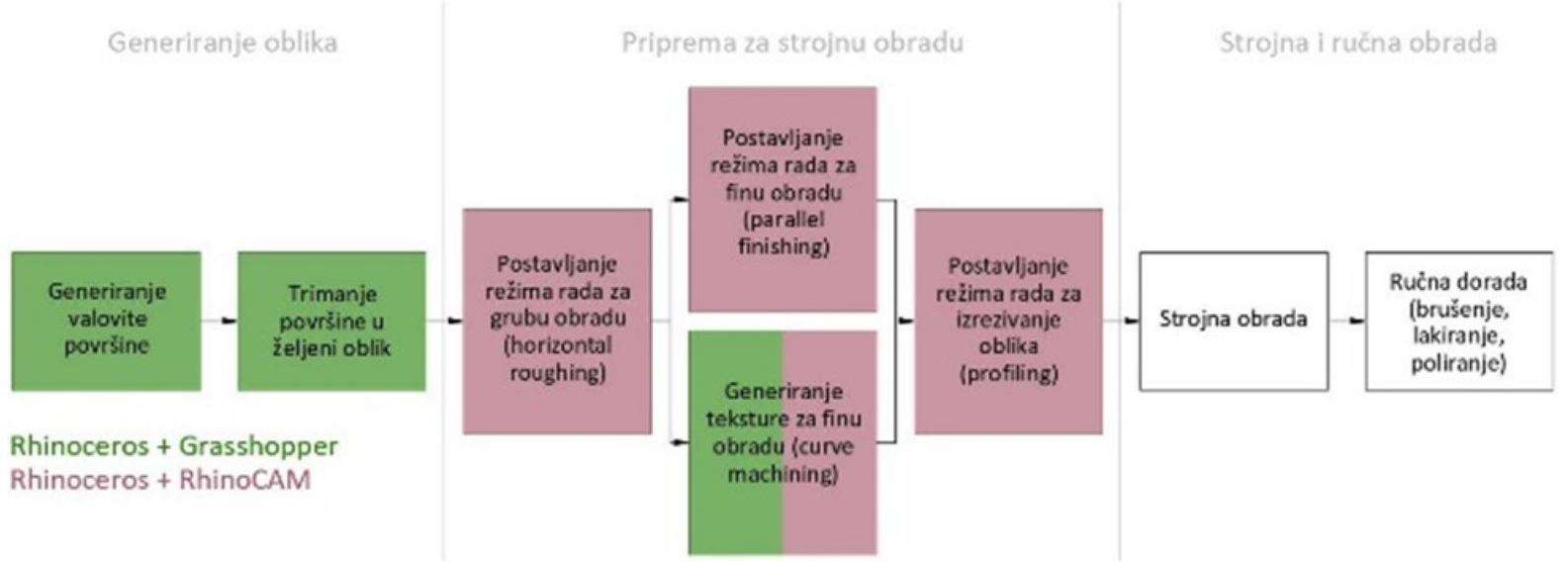

Slika 1. Dijagram slijeda operacija za proizvodnju primjerka zidnog panela

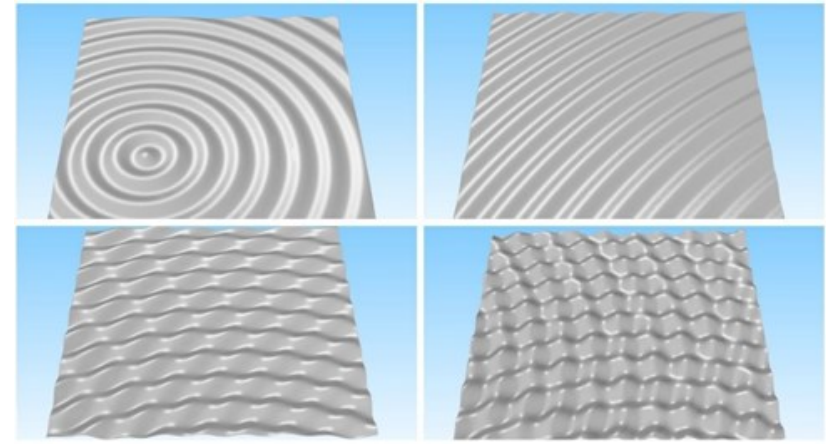

Slika 2 - Studija razvoja valovite površine (gore-desno prema dole-lijevo): 1) jedan izvor vala vidljiv na površini, 2) jedan izvor vala izvan vidljive površine, 3) dva izvora vala $u$ interferenciji, 4) tri izvora vala $u$ interferenciji

Izvor trećeg vala uz postavljanje ispravnih valnih duljina $\mathrm{i}$ amplitude dodaje kompleksna svojstva valovitoj površini. Dodatne modulacije na sinusnim funkcijama uvođenjem Garstner faktora i međusobnim zbrajanjem periodičnih funkcija dodatno razrađuju dinamiku vala. Apliciranjem ove funkcije na jedan do dva valna izvora značajno razbija monotonost i uvodi aperiodičnost i element kaotičnosti u model. Finim podešavanjem parametara definicije dobivaju se intrigantni i aperiodički valoviti uzorci koji po svojim profilima nalikuju na prave valove. Na slici 3 vidimo dva različita vala čije zbrojene amplitude rezultiraju potpuno novim nesimetričnim valnim profilom. Narančasti val rezultat je redovne funkcije:

$$
f(x)=\sin (x)
$$

Bijeli val sinusna je funkcija modulirana Garstnerovim faktorom. Garstner faktor (k) koristi se kada se želi postići šiljastiji vrh i dugačka dolina vala. Formula je sljedeća:

$$
f(x)=2\left(\frac{\sin (\mathrm{x})+1}{2}\right)^{k}
$$

Gdje $1.0<\mathrm{k}<2.5$ daje najbolje rezultate [2].

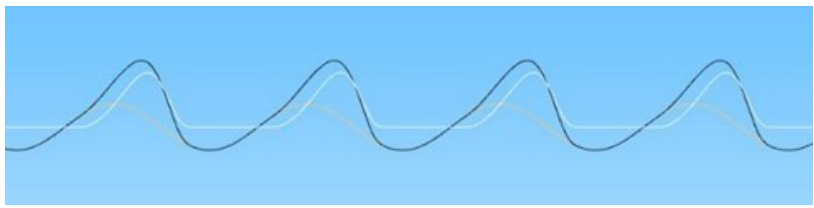

Slika 3. Zbrajanje i moduliranje sinusnih funkcija

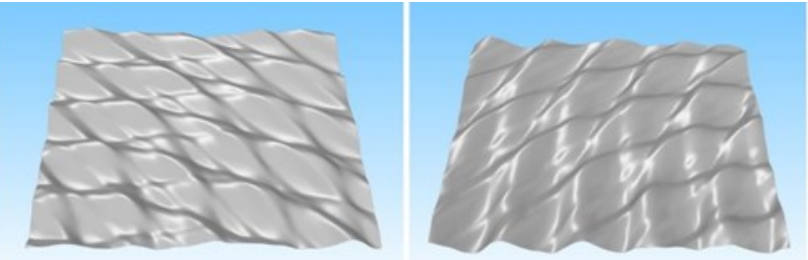

Slika 4. Studija razvoja valovite površine; Finalni rezultat

Izvedena valna površina potom je trimana i prilagođena kružnom obliku. Kružni oblik promjera $300 \mathrm{~mm}$ odabran je za testiranje i prezentaciju rezultata eksperimenta.

\subsection{Priprema za strojnu obradu}

Nakon izvedene valne površine, potrebno je napraviti pripremu za NC strojnu obradu. U tu svrhu korišten je RhinoCAM plugin.

Izvedba komada na NC stroju sastoji se od tri stadija:

1.) Gruba obrada (horizontal roughing)

2.) Fina/završna obrada (parallel finishing/curve machining)

3.) Izrezivanje komada (profiling)

Obrada materijala metodom skidanja/odvajanja čestica najčešće se odvija gore navedenim slijedom. Najprije se od stoga materijala (tzv. obradak) u grubom prolazu eliminira većina viška materijala.

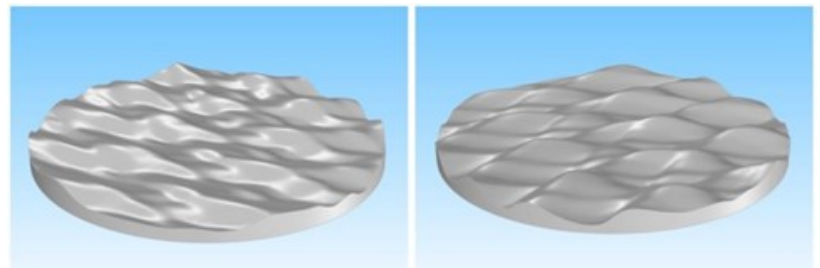

Slika 5. Izgled obradka nakon grube obrade
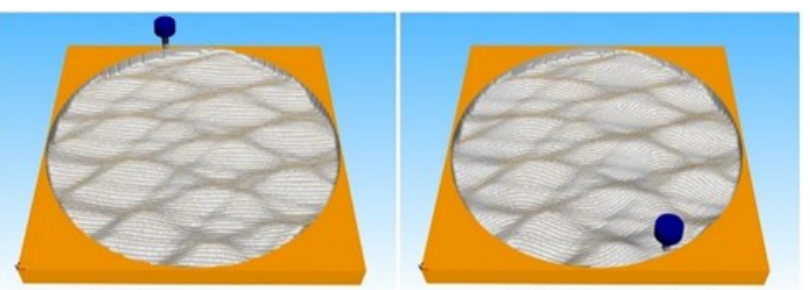

Slika 6. Usporedba obradaka urađenih različitim završnim režimom rada; Parallel finishing - lijevo; Curve machining - desno 
Završnu obradu moguće je uraditi na dva načina. RhinoCAM nudi mogućnost parallel finishinga, što znači da se za bilo koju danu površinu završna obrada vrši po paralelnim linijama projiciranim na površinu modela.

$\mathrm{Na}$ taj način se ostaci prvotno urađene grube obrade skidaju u pravilnim, jednako razmaknutim putanjama alata.

Korištenjem curve machining režima obrade za 3-osne strojeve, moguće je upravljati glavom stroja prema predefiniranoj krivulji uvezenoj iz Rhina.

Ovakav način završne obrade inicijalno je nešto zahtjevniji za postavljanje no može pružiti estetski prihvatljivije rezultate tako da ručno brušenje i zaglađivanje površine nakon strojne obrade nije potrebno.

\subsection{Strojna i ručna obrada}

Materijal, te njegova boja i tekstura visoko utječu na odabir parametara obrade. U slučaju rada sa prirodnim drvom poželjno je poštivati fizikalne i estetske karakteristike drva.

Prilikom postavljanja reznih parametara potrebno je voditi brigu o smjeru vlakana kao i o brzini izlaska alata iz materijala.

Kod drva je uvijek poželjno vršiti rezanje paralelno uz vlakna materijala. Rezanje koje se vrši poprečno na smjer vlakana drva ostavlja neurednu i ,raščupanu“ površinu, te rotacija alata ima tendenciju otkrhnuti veliki komad materijala.

Rezanje uz vlakno ostavlja glađu i čišću površinu i umanjuje mogućnost odvaljivanja velikih komada materijala. Kod istosmjernog glodanja smjer kretanja i rotacija glodala su isti, dok se kod protusmjernog glodanja obrada vrši u suprotnom smjeru od rotacije glodala.
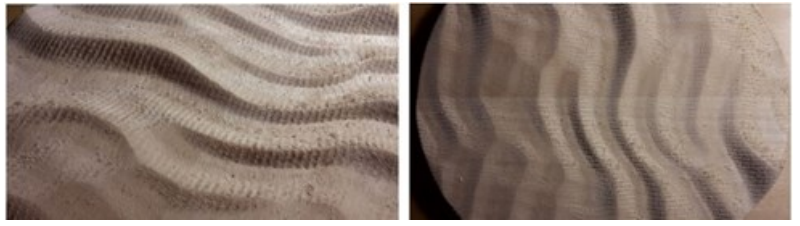

Slika 7. Pretjerano teksturiranje na prirodnom drvu može proizvesti zbunjujuće i neželjene rezultate.

Također, prirodno drvo kao materijal ima svoju inherentnu teksturalnu kvalitetu. Pretjerivanje sa teksturama završne strojne obrade mogu proizvesti zbunjujuće i nepoželjne rezultate zbog komplementarne naravi prirodnih i umjetnih tekstura.

Homogeni materijali bez izražene intrinzične teksture pogodniji su za strojnu obradu.

Kod mdf-a valovita površina dolazi više do izričaja, a homogena struktura ne stvara dodatne probleme prilikom definiranja režima obrade.
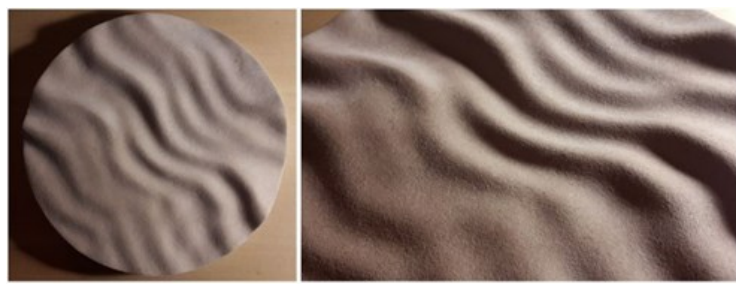

Slika 9. Teksturiranje valovima na ploči od MDF-a

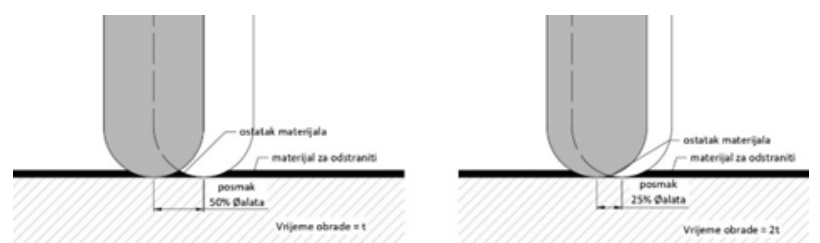

Slika 10. Ovisnost veličine lateralnog posmaka alata $i$ ostatka materijala kod glodanja polukružnim glodalom.

Kada završna obrada, kao u našem slučaju, za krajnji rezultat ima fino zaglađenu ili teksturiranu zakrivljenu površinu najpogodnije je koristiti polukružna ili kuglasta glodala. Kružni profil glodala teoretski stupa u kontakt sa površinom za obradu samo u jednoj točki.

Što je veći prodor glodala u površinu, veća je površina kontakta. Ukoliko je posmak između usporednih putanja glodala dovoljno malen, teoretski je moguće izglodati savršeno zakrivljenu površinu.

Sa smanjenjem posmaka glodala proporcionalno raste $\mathrm{i}$ vrijeme obrade, te je zbog toga poželjno koristiti teksturalne mogućnosti glodala prilikom proizvodnje dijelova kod kojih nije potrebno ostvariti visoke tolerancije ili glatkoću površine.
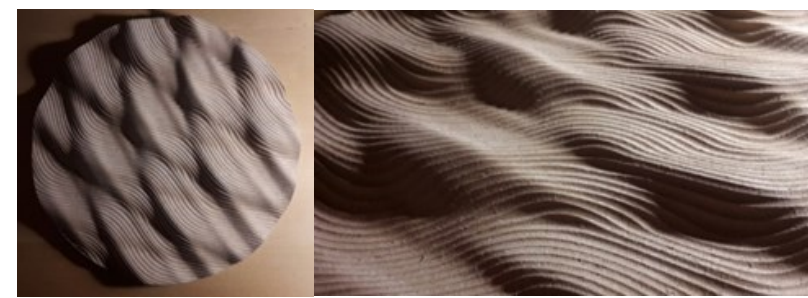

Slika 11. Zavř̌na obrada jednim skupom krivulja

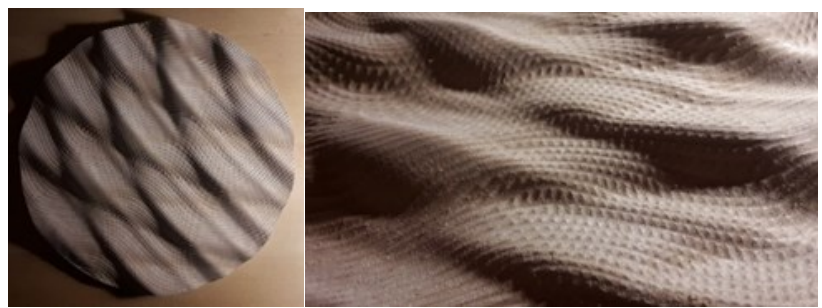

Slika 12. Završna obrada s dva skupa krivulja međusobno zakrenutih za 45 stupnjeva

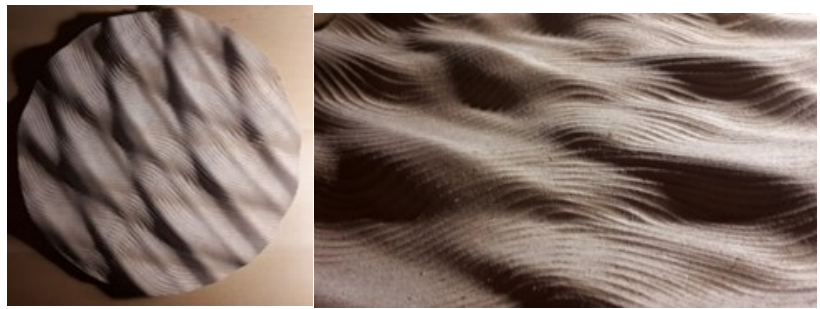

Slika 13. Završna obrada s dva skupa krivulja međusobno zakrenutih za 5 stupnjeva

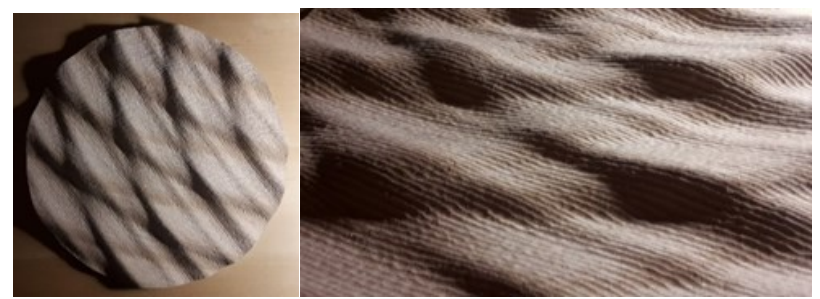

Slika 14 - Zavšna obrada paralelenim linijama 


\subsection{Rezultati}

U nastavku je dan pregled rezultata eksperimenta sa pripadajućim parametrima i režimima obrade.

\begin{tabular}{|l|l|}
\hline $\begin{array}{l}\text { Vrijeme obrade: } \\
\text { 56min }\end{array}$ & Alat: \\
\hline kružno glodalo Ø8mm brzina: & Režim rada: \\
1700mm/min & Curve machining \\
\hline Vrijeme obrade: & Alat: \\
70min & kružno glodalo Ø8mm \\
\hline Rezna brzina: & Režim rada: \\
1700mm/min & Curve machining \\
\hline Vrijeme obrade: & Alat: \\
65min & kružno glodalo Ø8mm \\
\hline Rezna brzina: & Režim rada: \\
$1700 \mathrm{~mm} / \mathrm{min}$ & Curve machining \\
\hline
\end{tabular}

\begin{tabular}{|l|l|}
\hline Vrijeme obrade: & Alat: \\
$85 \mathrm{~min}$ & kružno glodalo Ø8mm \\
\hline Rezna brzina: & Režim rada: \\
$1700 \mathrm{~mm} / \mathrm{min}$ & Parallel finishing \\
\hline
\end{tabular}

\section{ZAKLJUČAK}

Kroz praktičan rad pokazano je kako ornamentalne i dekorativne zidne panele možemo efikasno i precizno proizvesti uz minimalne tehnološko-materijalne zahtjeve. Efektnost i dojam razvedenosti površine daleko je podložniji upotrjebljenoj strategiji završne obrade nego površini na koju je aplicirana.

Završno skidanje materijala u valovitim putanjama dodaje dinamiku površini i konačno iskorištava potencijal strojne obrade $\mathrm{u}$ estetske svrhe. Ovo je najevidentnije kod usporednog promatranja 1. i 4. slučaja gdje je vrijeme obrade 15- 20 minuta kraće kod curve machininga nego kod parallel finishinga. Vrijeme obrade dodatno raste ukoliko dizajner želi u potpunosti zagladiti površinu bilo strojno ili ručno.

No, iako je vrijeme pripreme materijala i strojne obrade panela relativno kratko, procesi koji prethode samoj proizvodnji uzimaju glavninu radnog vremena $i$ zahtijevaju unaprijed usvojeno znanje iz područja parametarskog modeliranja, svojstava materijala i NC tehnologije obrade materijala.

Vrijeme generiranja oblika valovite površine može biti vremenski zahtjevno, ovisno o razini složenosti i dinamičnosti koju zahtjeva klijent, odnosno korisnik. Ipak, jednom kada su elementi unutar proizvodnog procesa usklađeni moguće je vrlo efikasno producirati male serije zidnih panela.

\section{LITERATURA}

[1] Di Marco, G., 2018. Simplified Complexity - Method for advanced NURBS modeling with Rhinoceros. 1st ur. Brienza (Potenza): Le Penseur Publisher.

[2] Finch, M. \& Worlds, C., 2007. Nvidia developer GPU gems. [Mrežno]

Available at: https://developer.nvidia.com/ gpugems/GPUGems/gpugems ch01.html

[Pokušaj pristupa 03112018 ].

[3] Gruber, P. \& Imhof, B., 2013. Biornametics Architecture Inspired by Natural Patterns. U: P. Gruber \& B. Imhof, ur. What is the Architect Doing in the Jungle? Biornametics. Wien NewYork: Springer Wien New York, pp. 22-31.

[4] Guidot, R., 2006. Industrial Design - Techniques and Materials. 1st ur. Paris: Flammarion.

[5] Levit, R., 2008. Contemporary Ornament: Return of the Symbolic Repressed. Harvard Design Magazine, May, I(28), pp. 70-85.

[6] Lynn, G., 2004. The Structure of the Ornament [Intervju] 2004.

[7] Moussavi, F. \& Kubo, M., 2006. The Function of Ornament. 1st ur. Barcelona: Actar.

[8] Picon, A., 2013. Ornament: The Politics of Architecture and Subjectivity. 1st ur. Chichester: John Wiley and Sons.

[9] Tedeschi, A., 2014. AAD_Algorithms-Aided Design. 1st ur. Brienza (Potenza): Le Penseur Publisher.

\section{Kratka biografija:}

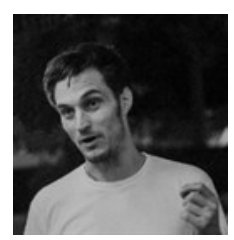

Andrija Mihelčić rođen je u Rijeci 1988.god. Diplomirao je na Sveučilišnom odsjeku za Politehniku u Rijeci na temu Fotonaponske solarne elektrane 2014.god. Master rad na Fakultetu tehničkih nauka u Novom Sadu iz oblasti Digitalne tehnike, dizajn i produkcija u arhitekturi i urbanizmu odbranio je 2019.god 